\title{
Las medidas provisionales y cautelares: A propósito de ciertos aspectos recurren- tes en el arbitraje de inversiones
}

\author{
Alexis Mourre y Alexandre Vagenheim \\ Castaldi Mourre \& Partners
}

\section{Sumario:}

1. Introducción. 2. Las condiciones para conceder medidas provisionales y cautelares. 2.1 El examen prima facie de la competencia del tribunal arbitral. 2.2 Condiciones del otorgamiento de la medida. 2.3 ¿Recomendar u ordenar? 3. El exclusivismo imperfecto del Convenio de Washington en materia de medidas provisionales y cautelares. 4. La cuestión de las medidas ex parte. 5. EI poder de los árbitros para dictar órdenes y penas coercitivas. 5.1 Anti-suit injunctions y procedimientos paralelos. 5.2 Poder de los árbitros para dictar órdenes, multas coercitivas y ejecución específica. 6. La constitución de garantías.

\section{INTRODUCCIÓN}

Con el aumento de la duración y de la complejidad de los procedimientos arbitrales, cada vez es más frecuente que las partes recurran a las medidas provisionales, para proteger sus derechos durante el procedimiento. El poder de ordenar tales medidas es inherente al ejercicio de la juris dictio, sea por el juez o por el árbitro.

Tales medidas, cuya variedad es amplia, se caracterizan en primer lugar por su carácter no definitivo, y por tanto, por el 
hecho de que el juez o el árbitro pueden en todo momento modificarlas o revocarlas.

La ley-tipo de la CNUDMI, según su redacción actual, luego de las reformas adoptadas en 2006, define la medida provisional como una "medida temporal", por la cual el tribunal arbitral ordena a una parte que

“a) mantenga o restablezca el status quo en espera de que se dirima la controversia; b) adopte medidas para impedir algún daño actual o inminente o el menoscabo del procedimiento arbitral, o que se abstenga de llevar a cabo ciertos actos que probablemente ocasionarian dicho daño o menoscabo al procedimiento arbitral; c) proporcione algún medio para preservar bienes que permitan ejecutar todo laudo subsiguiente; o d) preserve elementos de prueba que pudieran ser relevantes y pertinentes para resolver la controversia"1.

Estas medidas se caracterizan igualmente por el objetivo que persiguen, el cual es preservar los derechos de alguna o algunas de las partes. Lo que se acentúa, entonces, es su carácter cautelar. Así, el reglamento de arbitraje de la CCI hace referencia a los términos "cautelares y provisionales" 2 . La Ley federal suiza sobre Derecho Internacional Privado, y el Decreto francés del 13 de enero de 2011 hacen también referencia a medidas "cautelares o provisionales" 3 . El Derecho de la Unión Europea expresa claramente esta dimensión funcional al caracterizar estas medidas como aquellas "destinadas a mantener una situación de hecho o de derecho a fin de salvaguardar los derechos cuyo reconocimiento además está siendo solicitado al juez del fondo"4.

El recurso a las medidas cautelares y provisionales no es nuevo en Derecho Internacional Público. El artículo $41 \S 1$ de los Estatutos de la Corte Internacional de Justicia ("CIJ") ya dispo-

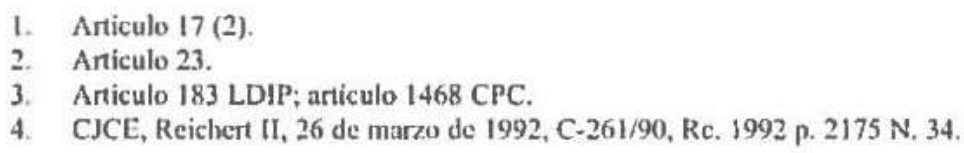


nía que "La Corte tendrá facultad para indicar, si considera que las circunstancias así lo exigen, las medidas provisionales que deban tomarse para resguardar los derechos de cada una de las partes".

Seguidamente, dichas medidas encontraron su lugar en la Convención de Washington del 18 de marzo de 1965; esta última sin embargo tomó en consideración la particular naturaleza del arbitraje entre inversionistas y Estados, limitando el poder de los árbitros a la formulación de "recomendaciones", término menos prescriptivo que aquellos de orden o decisión. Esta marca de deferencia hacia la soberanía de los Estados se expresa en el artículo 47 del Convenio de Washington, el cual dispone que, "salvo acuerdo en contrario de las partes, el Tribunal, si considera que las circunstancias así lo requieren, podrá recomendar la adopción de aquellas medidas provisionales que considere necesarias para salvaguardar los respectivos derechos de las partes".

Las medidas provisionales o cautelares que puedan ser ordenadas durante el arbitraje pueden referirse tanto a la administración del procedimiento como a los derechos sustanciales de las partes. Ciertos tribunales parecen haber considerado que el artículo 47 de la Convención de Washington tiene un campo de aplicación extenso y se aplica indiferentemente a la preservación de derechos substanciales de las partes y a la administración de la prueba. En el caso Bizuater, el tribunal arbitral consideró así, que:

“la precisa línea divisoria entre lo que es (i) propiamente una medida provisional bajo el Artículo 47 y (ii) una orden bajo el Artículo 43, puede no siempre ser inmediatamente obvia. Esto es aún más patente tomando en cuenta que (como se explicó arriba) el Artículo 47 se extiende a la protección de derechos procesales respecto de la evidencia, y que en el pasado, los tribunales que han formulado recomendaciones para la reunión y preservación de la evidencia según el Artículo 47 (posiblemente) también hubieran podido formularlas en virtud del Artículo 43"5. 
Las medidas protisionales y cautchares:

A propósito de cierios aspectos recurrentes en el arbitraje de inzersiones

Sin embargo, es posible pensar que los redactores del Convenio quisieron someter las solicitudes de tipo probatorio a un régimen particular. En este sentido, el artículo 43 del Convenio hace referencia al poder del tribunal arbitral para ordenar la producción de pruebas, de visitar todos los lugares relacionados con el litigio y de llevar a cabo todas las investigaciones, y el artículo 19 del Reglamento de Arbitraje prevé que el tribunal puede dictar todas las órdenes necesarias para conducir el procedimiento. Como veremos, esta distinción puede no estar totalmente desprovista de consecuencias.

El presente artículo no tiene por objeto abarcar todas las cuestiones relativas a las medidas provisionales y cautelares en el arbitraje de inversiones, ya que las mismas han sido objeto de exhaustivos análisis en otros trabajos 6 . Nosotros nos limitaremos a abordar ciertas cuestiones específicas que consideramos merecen una reflexión particular.

Luego de hacer un recordatorio general de las condiciones requeridas para acordar medidas provisionales y cautelares en el arbitraje de inversiones (2), nos referiremos a la imperfecta exclusividad de competencia que tienen los tribunales arbitrales del CIADI en la materia (3), al poder de los árbitros para ordenar medidas ex parte en presencia de un Estado (4), al poder de los árbitros para dictar órdenes, de las penas coercitivas, y de la ejecución específica en materia de inversiones internacionales (5), y finalmente, a las medidas que ordenan la constitución de garantías (6).

5. Biwaler Gauff (Tanzanic) Limiled v. United Republic of Tanzania, Caso CIADI ARB/05/22, orden de procedimiento $n^{\circ} 1, \$ 80$ (traducción libre), adde, Ch. SClireUER y otros. The ICSID Convention: A commentary on the Convention on the Settement of Investment Disputes befween States and Nationals of Other Statcs, Cambridge, 2009, $\$ 80$, p. 780.

6. A. ANTONIEITI, " ICSID and Provisional Measures: An Overview ", Im. Law Forum, 2005, vol. 7, p. 10.- R. ZIADÉ, " Mesures provisoires et consenatoires (tribunal arbitral et rribunal ćtatique) ", La procedure arbitrale relative aux investissements internationaux: aspects recents, Ch. LeBEN (dir.), LGDJ/Anthemis, 2009, L. MAL.INTUPP, "Provisional measures in recent ICSID procecdings: what parties request and what tribunals order ", en International hnestment Law for the 2Ist Century : Essays in Honour of Christoph Schreuer, Ch. Binier et al (eds), Oxford University Press, 2009, pp. 157-184. 


\section{LAS CONDICIONES PARA CONCEDER MEDIDAS PROVI- SIONALES Y CAUTELARES}

El artículo 39 del Reglamento de Arbitraje CIADI prevé que el tribunal arbitral puede dictar medidas provisionales o cautelares a la solicitud de una de las partes ${ }^{7}$ o por su propia iniciati$\mathrm{va}^{8}$ (artículo 39.3), siendo esta última hipótesis más bien excepcional en la práctica.

La multiplicación de solicitudes de este tipo ha permitido a los tribunales del CIADI desarrollar progresivamente las condiciones bajo las cuales estas pueden ser admitidas. Nosotros nos limitaremos aquí a tratar sobre las cuestiones que se presentan con mayor frecuencia. Examinaremos en primer lugar la apreciación printa facie del tribunal arbitral sobre su propia competencia (2.1), luego el control ejercido por el tribunal de acuerdo a la medida solicitada (2.2). Finalmente nos interrogaremos sobre el significado de la noción de "recomendación" en el arbitraje CIADI (2.3).

\subsection{El examen prima facie de la competencia del tribunal arbi- tral}

Cuando la competencia del tribunal arbitral no es impugnada o cuando este último ya se ha pronunciado sobre su competencia, el mismo es, en principio, competente para adoptar las medidas provisionales o cautelares. Puede ocurrir, sin embargo, que tales solicitudes sean presentadas aun cuando la competencia del tribunal no ha sido todavía establecida. En tales casos, ¿puede el tribunal pronunciarse inmediatamente? El artículo 39.2 del Reglamento impone al tribunal arbitral dar prioridad al tratamiento de la solicitud de medidas provisionales o cautelares. El tribunal arbitral podrá entonces encontrarse en la situación de tener que pronunciarse sobre la solicitud de medidas

7. Articulo 39 (1) del Reglamento de Arbitraje CIADI.

8. Artículo 39 (3) del Reglamento de Arbitraje CIADI. 
Las medidas provisionales y cautelares:

A proposito de ciertos aspectos recurrentes en el arbitraje de inversiones

provisionales antes de haberse pronunciado sobre su competencia en cuanto al fondo ${ }^{9}$, pero, al hacer esto, ¿no estaría prejuzgando su decisión subsiguiente respecto de esta última cuestión?

Los árbitros, para resolver este problema, han recurrido al método del control prima facie de su propia competencia ${ }^{10}$. En el caso Chevron c. la República de Ecuador, el tribunal arbitral estimó entonces que

“para el limitado propósito de la presente decisión, el Tribunal asume provisionalmente que tiene jurisdicción para decidir sobre la Segunda Solicitud de Medidas Provisionales de los Demandantes en base a que los Demandantes han establecido satisfactoriamente para el Tribunal, un caso suficiente para la existencia de tal competencia en esta etapa preliminar del procedimiento arbitral".11

Este método permite a los árbitros verificar que no son manifiestamente incompetentes, y evitar así, adoptar medidas que estarían destinadas a ser revocadas, y que pudieran ocasionar un perjuicio al demandado.

Tal control, comparable en ciertos aspectos a aquél que ejercen ciertas instituciones de arbitraje cuando deciden continuar el procedimiento en presencia de una impugnación sobre la competencia del tribunal ${ }^{12}$, o a aquél ejercido por el juez de apoyo en los países que reconocen el efecto negativo del principio compétence-compétence ${ }^{13}$, presenta un carácter preliminar por su natu-

9. Ver por ejemplo: Holiday Inns S.A. Occidental Petrolcum Corporation et al. v. Govemment of Morocco; caso No. ARB/72/1 § 50, D. 2 de julio de 1972, el tribunal « es competente para ordenar medidas provisionales $"$, pero " las panes conservan el derecho [...] de presentar, durante la continuación del procedimiento, toda excepción relativa a la competencia del Tribunal sobre cualquier otro aspecto del litigio " (traducción libre) en P. LALIVE, " The First World Bank Arbitration (Holiday Inns v. Morocco) - Some Legal Problems n, British Yearbook of International Law, 1980, pp. 123 y ss.

10. Ver por ejemplo: Ford Acrospacev v. The Air Forec of Iran, Caso No. 159 Tribunal de Reclamaciones EE.UU.-Irán, Laudo prelimirar No. ITM 39-159-3, 4 de junio de 1984; Holiday Inns c, Royaume du Maroc, 2 de Julio de 1972, en P. Lalive, op. cit. pp. 123 y ss.

11. Chevron Corp, and Texaco Petroleum Co. v. The Republic of Ėcuador. Caso de la CPA n ${ }^{\circ} 2009-23$. Orden del 9 de febrero de 2011 (Iraducción libre). Ver en Internet:

(hitp:/italaw.com/documents/ChevronAndTexacoVIecuador_InterimMeasuresOrucr.pdi)

12. Ver por ejemplo el articulo 6 (2) del Reglamento CCl.

13. En Francia, ver el articulo 1.448 CPC. 
raleza y no prejuzga en nada la futura decisión del tribunal arbitral sobre su propia competencia. En el caso Vacumm Salt c. République du Ghana, el tribunal ordenó así ciertas medidas provisionales ${ }^{14}$ antes de declararse incompetente rationae materine ${ }^{15}$. En el caso Pey Casado c. República de Chile, el tribunal estimó que:

"las medidas provisionales, las cuales son provisionales por naturaleza y definición (tal como lo observa con acierto la parte demandada), las puede modificar o anular en todo momento el Tribunal, no tienen fuerza de 'res judicatn', sólo permanecen vigentes durante el procedimiento, y "quedan automáticamente sin efecto" si el Tribunal de Arbitraje se declara incompetente para conocer de la controversia." 16

La jurisprudencia de la $\mathrm{CIJ}$ ha confirmado que en presencia de una objeción sobre su propia competencia, el tribunal arbitral puede sin embargo pronunciar medidas provisionales y cautelares luego de una verificación prima facie de su competencia. En su decisión sobre el caso relativo a las Fábricas de pasta de papel sobre el río de Uruguay (Argentina c. Uruguay), la Corte señaló:

"para pronunciarse sobre una solicitud de medidas cautelares, la Corte no necesita asegurarse de manera definitiva de tener competencia para conocer sobre el fondo del caso, sino que podrá hacerlo en la medida en que exista, prima facie, una base sobre la cual pueda fundamentar su competencia". ${ }^{17}$

El arbitraje del CIADI presenta sin embargo la particularidad de que un control prima facic ya ha sido ejercido por el Centro al momento de registrar la demanda. Toda demanda de arbitraje debe, en efecto, según el artículo 36 (3) del Convenio de

14. Vacuum Sait Products, Lld. c. Ghana, Caso CIADI ARB/92/1, Decisión sobrc las medidas cautciares del 14 de junio de 1993.

15. Vacuum Sait Products, Led, c. Ghana, prec., Laudo de 16 de febrero de 1994.

16. Victor Pcy Casado y Fundacion Presidente Alicnde c. República de Chilc, Caso CIADI ARB 98/2, Decisión sobre las medidas provisionales solicitadas por las partes, 25 de septiembre de 2001, $\$ 14$; ICSID Review, 2001, p. 567.

17. Usines de päte d papier sur le feuve Uruguay (Argentine c. Unuguay), Corte Internacional de Justicia, orden sobre medidas cautelares, 23 de enero de 2007, $\$ 24$ (traducción libre). 
Washington, someterse a un examen preliminar por la Secretaría General, respecto de la competencia del Centro, y la Secretaría no permitirá la admisión de la demanda si considera "que la controversia se halla manifiestamente fuera de la jurisdicción del Centro".

El Secretario General verificará entonces, en particular, sobre la nacionalidad del demandante y el contenido de la demanda, y si la misma corresponde aparentemente a la competencia del Centro. Tal control prima facie, ¿dispensará a los árbitros de verificar a su vez que ellos no son manifiestamente incompetentes cuando deban pronunciarse sobre una solicitud de medidas provisionales o cautelares mientras que su competencia está siendo cuestionada en cuanto al fondo?

El registro hecho por la Secretaría General no vincula al tribunal arbitral, el cual se mantendrá libre para declararse incompetente. En principio, ocurre lo mismo al momento de la apreciación primn facie por el tribunal sobre su propia competencia en el marco de una solicitud de medidas provisionales o cautelares. Sin embargo, el control prima facie ejercido por los árbitros se asemeja por su naturaleza y su contenido de aquél que ejerce la Secretaría General en aplicación del artículo 36. Muchos autores ven, por cierto, en el registro de la demanda por la Secretaría General, una presunción prima facie de la existencia de competencia18.

El control, de naturaleza administrativa, ejercido por la Secretaría General no podrá sin embargo dispensar al tribunal arbitral -que ejerce una función jurisdiccional- de efectuar sus propias verificaciones ${ }^{19}$.

18. Ch. SCIHEUER y otros, The ICSID Convention: A commentary on the Convention on the Settement of Investment Disputes between States and Nationals of Otiker States, prec. p. 772.

19. Ver Ch. Brower y R.E.M. Gomman "Provisional Measures and the Protection of ICSID Jurisdictional Exclusivity Against Municipal Proceedings". ICSID Revicw 6, 1991, p. 431, v. sin embargo más matizado, R. ZıADt, op. cit., p. 201. 
El tribunal del caso Pey Casado c. Chile, luego de haber señalado que el examen preliminar de la competencia del CIADI "se aproxima, en cierta medida y a pesar de las diferencias en cada situación, al test 'prima facie' de la Corte Internacional de Justicia", observó correctamente que,

"el registro efectuado por el Secretario General del CIADI no obliga a nada al Tribunal de Arbitraje, ni lo exime, en caso de que su competencia sea objetada, de asegurarse de que ésta existe prima facie o, expresado en términos negativos, de que no exista incompetencia manifiesta" 20 .

El tribunal del caso Occidental c. Ecuador estimó por su parte que:

"Si bien no es necesario que el Tribunal concluya que posee competencia para entender en el fondo del asunto a fin de pronunciarse sobre las medidas provisionales que se solicitan, se abstendrá de disponer tales medidas a menos que exista, prima facie, una base que permita establecer su jurisdicción"21.

\subsection{Condiciones del otorgamiento de la medida}

El Convenio de Washington y el Reglamento de Arbitraje del CIADI no precisan los derechos susceptibles de ser objeto de una medida de protección. El artículo 39 (1) del Reglamento apenas impone a la parte solicitante, identificarlos. Tales derechos alegados podrán sin embargo ser impugnados. Los árbitros se encontrarán entonces confrontados a la situación de tener que determinar el nivel de prueba exigido por la parte demandada en el marco de una solicitud de medida provisional o conservatoria.

20. Victor Pey Casado y Fundación Presidente Allende c. Repuiblica de Chile, decisión sobre las medidas provisionales solicitadas por las parts's,

21. Occidental Petroleum Corporation y Occidental Exploration and Production Company c. República del Ecuador, Caso CIADI ARB/06/II, decisiỏn sobre medidas cautelares, 17 de agosto de 2007, 55 . 


$$
\begin{aligned}
& \text { Las medidas provisionales y cautelares: } \\
& \text { A propósito de ciertos aspectos recurrentes en el arbitraje de inversiones }
\end{aligned}
$$

En el caso Maffezini c. Reino de España, los árbitros parecen haber exigido que sea satisfecha la prueba de la existencia de los derechos cuya protección es solicitada a título provisional. Según el tribunal, tales derechos no podrían ser "hipotéticos" y debían existir al momento de la solicitud.

Este enfoque fue criticado por el tribunal en el caso Pey Casado c. Chile, que consideró que

"el Tribunal de Arbitraje no podría exigir, como una condición previa al otorgamiento de una recomendación, de acuerdo con la regla 39 del Reglamento, la prueba por parte del solicitante de la existencia, de la realidad o de la actualidad de los derechos que la medida solicitada pretende salvaguardar o proteger" 22 .

\section{Para el tribunal en Pey Casado,}

"Exigir que el derecho que se pretende salvaguardar sea existente, haya sido demostrado o comprobado 'al momento de la solicitud', puede ciertamente, en algunas circunstancias, no acarrear dificultad alguna. Sin embargo, en otras circunstancias, podría, ex natura rerum, obligar al Tribunal de Arbitraje a prejuzgar sobre el fondo, en un momento en donde precisamente no está en medida de juzgar, y bajo hipótesis en las que, por definición, la constancia o prueba de la existencia o realidad del derecho invocado no podría aportarse más que más tarde, mediante el laudo arbitral sobre el fondo del asunto." 23

La dificultad a la que se encuentran confrontados los árbitros aquí es comparable a aquella que les lleva a verificar prima faciesu competencia. La parte que solicita una medida provisional o conservatoria no podrá ser dispensada de toda carga de la prueba en cuanto a la existencia de derechos cuya protección es soli-

22. Victor Pey Casado y Fundacioin Presidentc Allende c. Repuiblica de Chile, Caso CIADI ARB/98/2, prec. $\$ 46$.

23. Victor Pcy Casado y Fundación Presidente Allende c. República de Chile, Caso ClADI ARB/98/2. prec. $\$ 48$. 
citada, pero no podemos tampoco exigir de ella, que lleve a cabo una demostración definitiva de su buen derecho, tal demostración supondría una instrucción completa del caso, incompatible con la celeridad requerida en el marco del contencioso de medidas cautelares. En este nivel, los árbitros se limitan a verificar que los derechos litigiosos sean susceptibles de ser establecidos, más que probados de manera cierta ${ }^{24}$.

La otra cuestión que se plantea frecuentemente es la de la demostración de la urgencia y la existencia de un riesgo de ocasionar un perjuicio irreparable. Estas condiciones son propias del contencioso de las medidas cautelares, y no tienen lugar, evidentemente, cuando se trata de preservar pruebas ${ }^{25}$.

El examen de la práctica de los tribunales arbitrales muestra que la admisión de las solicitudes de medidas provisionales y cautelares generalmente está condicionada al doble requisito de urgencia y de existencia de un riesgo de perjuicio irreparable. La carga de la prueba de estas condiciones pesa sobre la parte solicitante ${ }^{26}$.

Tratándose de la urgencia, el profesor SCHREUER estima que, aun cuando los redactores del Convenio de Washington no hicieron referencia explícita a la misma, las medidas provisionales no pueden ser apropiadas salvo cuando se refieren a asuntos que no pueden esperar por la decisión sobre el fondo ${ }^{27}$. Este enfoque es generalmente compartido, pero los tribunales se muestran flexibles en su aplicación. El tribunal del caso Bizuater estimó al respecto que si bien es "constante" que la urgencia constituye "un criterio" para otorgar las medidas provisionales o cautelares, el nivel de urgencia requerido depende de las cir-

24. En este sentido, Victor Pey Casado y Fundacion Presidente Allende c. Republica de Chile, Caso ClADI ARB/98/2, prec, $\$ 64$.

25. Ver por ejemplo Art. 17.a.2. de la Ley-tipo CNUDMI que excluye para este tipo de medidas las condiciones del Articulo 17.a.1.

26. Emilio Agustín Maffezini c. Reino de España, Caso CIADI ARB/97/7, decisión sobre una solicitud de medidas cautelares, 28 de octubre de 1999, $\$ 10$.

27. Ver Ch. SCHREUer et al, The ICSID Convention: A commentary on the Convention on the Settement of Investment Disputes between States and Nationals of Other States, op cit., p. 775. 


\title{
Las medidas provisionalcs y cautelares: \\ A propósilo de cierlos aspeclos recurrentes cn el arbilraje de inversiones
}

cunstancias y puede ser satisfecho cuando una parte está en condiciones de probar que es necesario obtener la medida demandada antes que sea dictado el laudo final ${ }^{28}$.

Los tribunales aprecian caso por caso si la condición de urgencia ha sido satisfecha. Como indicó el tribunal de Bizuater:

\begin{abstract}
"según la perspectiva del Tribunal Arbitral, el grado de 'urgencia' que se requiere depende de las circunstancias, incluyendo las medidas provisionales solicitadas, y puede ser satisfecha cuando una parte pueda probar que existe una necesidad de obtener la medida solicitada en un cierto momento en el procedimiento antes de que se dicte el laudo. En la mayoría de las situaciones, esto equivaldrá a 'urgencia' en su sentido tradicional (i.e. la necesidad de la medida en un corto período de tiempo). En algunos casos, sin embargo, el único constreñimiento temporal es que la medida sea otorgada antes de que se dicte el laudo - aunque el otorgamiento sea de aquí a cierto tiempo. El Tribunal Arbitral también considera que el nivel de urgencia requerido depende del tipo de medida solicitada." 29
\end{abstract}

En cuanto a la prueba de la existencia de un riesgo de daño irreparable, el tribunal del caso Railrond Development Corp c. Guatemala precisó que la misma debía, igualmente, ser apreciada de manera razonable y según las circunstancias del caso:

"En vista de que en el texto de la Convención CIADI no se califican los poderes de los Tribunales CIADI para recomendar medidas provisionales, el estándar aplicable será uno de razonabilidad, luego de haberse considerado todas las circunstancias de la solicitud y luego de haberse tomado en cuenta los derechos que deben protegerse y la susceptibilidad de que se produzca un daño irreparable si el tribunal dejara de emitir una recomendación." 30

28. Bisater Gauff Ltd. c. Tanzania, orden procesal n 1, prec. $\$ 76$ (traducción libre).

29. Ibidem

30. Railroad Development Corporation c. República de Guatemala, Caso CIADI n ARB/07/23, decisión sobre las medidas provisionales, $15 \mathrm{de}$ octubre de 2008, $\$ 33$ (traducción libre). 
Ciertos tribunales se han centrado en la apreciación negativa de si la condición ha sido o no satisfecha: de esta manera, no sería irreparable todo daño que pueda ser reparado mediante su equivalente ${ }^{31}$. El tribunal de Plama estimó así que "el daño no es irreparable si puede ser indennizado económicamente" 32 . Semejante enfoque pudiera, sin embargo, parecer demasiado rígido. En efecto, es poco frecuente que un daño no pueda ser reparado mediante su equivalente. Pero puede ocurrir, sin embargo, que tal reparación resulte difícil o excesivamente onerosa. Los tribunales que han decidido respecto de solicitudes de medidas cautelares deberían entonces tener en consideración la eficacia de su decisión así como el principio según el cual las partes tienen el deber de no agravar la controversia.

Podemos congratularnos de la flexibilidad y la prudencia de la que dan muestra los tribunales del CIADI en materia de medidas cautelares. Por una parte, las condiciones de urgencia y de riesgo de daño irreparable son apreciadas con flexibilidad. Pero, por otra parte, los árbitros no dictan las medidas solicitadas salvo en los casos en que estas son indispensables para evitar que la situación de una parte se agrave o para preservar el statu quo. Los árbitros son conscientes que las solicitudes de medidas provisionales podrían llevarles a adoptar apreciaciones sobre las cuestiones en litigio que podrían colocarles en una situación difícilal momento de pronunciarse sobre el fondo. Igualmente existe el riesgo de que, luego de haberse pronunciado a título provisional, el tribunal en lo sucesivo sea inconscientemente reticente a contradecirse. Además, siempre existe un riesgo real de que una medida cautelar adoptada para proteger los derechos de una parte, termine ocasionando un perjuicio a la otra parte, que difícilmente podrá ser reparado, en caso de que finalmente se demuestre que no era justificada y sea anulada. Las partes, por tanto, podrán verse motivadas, al momento de solicitar una

31. Ver R. ZıADE, op.cit, p. 204, el autor describe el origen de esta condición en la jurisprudencia de la CIJ.

32. Plama Consonium Limited c. Bulgaric, Caso $\mathrm{CIADI} n^{\circ} \mathrm{ARB} / 03 / 24$, dccisión sobre la solicitud por parte del demandante de medidas provisionales urgentes, 6 de septicmbre de 2005 , $\$ 46$ (traducción libre). 
medida provisional o conservatoria, por consideraciones puramente tácticas.

Los árbitros deben entonces sopesar con la mayor prudencia todos los intereses en juego antes de acordar tales solicitudes. Deberán, en particular, guardarse de tomar posición sobre las cuestiones en litigio de tal manera que ello pueda afectar su independencia de espíritu a los ojos de las partes ${ }^{33}$.

\section{$2.3 i$ Recomendar $\mathrm{u}$ ordenar?}

El artículo 47 del Convenio de Washington y el artículo 39 del Reglamento de Arbitraje prevén que las medidas provisionales o cautelares sean tomadas bajo la forma de una recomendación. La elección de este término indica la intención de los redactores del Convenio de no conferir a los árbitros el poder de ordenar tales medidas ${ }^{34}$. Según ciertos autores ${ }^{35}$, esta reserva se compensaba por la obligación de los Estados, derivada de su consentimiento al arbitraje CIADI, de someterse a toda medida ordenada por el tribunal arbitral. Es según este espíritu que se ha desarrollado la jurisprudencia del Centro, la cual ha terminado por borrar el debate semántico para dar preferencia al carácter obligatorio de las decisiones provisionales dictadas por los árbitros.

El tribunal de Maffezini estimó así que:

"Si bien existe una diferencia semántica entre la expresión 'recomendar' empleada en la Regla 39 y la expresión 'dictar' utilizada en otras partes de las Reglas para describir la facultad del Tribunal para exigir a una parte que realice una acción determinada, dicha diferencia es más aparente que real. Incluso debe observarse que el texto de esa Regla en castellano utiliza, además, la expresión 'dictación'. El Tribunal

33. Sobre el riesgo de recusación que se deriva de una adopción de posición prima facie sobre las cuestiones en litigio, ver Alexis Mouret:, "Provisional Measures and Duty of Impartiality ", LClA Newsletter, 2007/2, pp. $22-24$

34. Ver Ch. SCuREut:R y otros, op. cit., p. $764, \$ 16$.

35. Ver Ch. SChrluer y otros, op. cit., p. 764 
no considera que las partes en el Convenio hayan querido establecer una diferencia substancial en el efecto de estas dos palabras. La autoridad del Tribunal para decidir sobre la adopción de medidas provisionales no es menos obligatoria que la de un laudo arbitral definitivo. Por consiguiente, para los efectos de la presente Resolución Procesal, el Tribunal estima que la palabra 'recomendar' tiene un valor equivalente al de la palabra 'dictar'36".

En el caso Tokios Tokelesc. Ukraine, el tribunal también estimó que:

"según un principio bien establecido por la jurisprudencia de los tribunales CIADI, las medidas provisionales 'recomendadas' por un tribunal CIADI son legalmente obligatorias; ellas son, efectivamente 'ordenadas' por el tribunal, y las partes están bajo la obligación legal de cumplirlas."37

No parece por tanto que exista una verdadera distinción entre recomendaciones y decisiones, las cuales tienen, ambas, carácter obligatorio para las partes. Podemos observar en este sentido que el artículo 46 (3) del Reglamento de Arbitraje del Mecanismo Complementario del CIADI emplea ambos términos de manera equivalente cuando dispone que "el Tribunal ordenará o recomendará medidas provisionales, o la modificación o revocación de las mismas, solamente después de haber concedido a cada parte una oportunidad para que presente sus observaciones". Sin embargo, ciertamente resulta lamentable el empleo de dos términos diferentes para definir una misma realidad. De esta manera, el tribunal de Bituater empleó, sin que ello respondiera aparentemente a ninguna justificación, los términos 'ordenar' y 'recomendar' para diferentes medidas ordenadas en la misma decisión ${ }^{38}$.

36. Emilio Agustín Maffezini c. Rcino de España, Caso CIADI ARB/97/7, decisión sobre una solicitud de medidas cautelares, 28 de octubre de 1999,89 .

37. Tokios Tokelès c. Ukraine, Caso CIADI ARB/02/18, orden procesul n I, I de julio de $2003, \$ 4$.

38. Biwater GaufT (Tanzania) Limited c. Tanzania, prec., orden procesal $\mathrm{n}^{\circ} \mathrm{I}, \S \S 88,98,106,114$. 
Lns untdidas provisionales y cautelares:

A proposito de ciertos aspectos recurrentes en d arbitraje de inversiones

\section{El exclusivismo imperfecto del Convenio de WASHINGTON EN MATERIA DE MEDIDAS PROVISIO- NALES Y CAUTELARES}

El arbitraje del CIADI se distingue del arbitraje comercial internacional, en materia de medidas provisionales y cautelares, por la prohibición hecha a las partes, salvo acuerdo contrario, de recurrir a las jurisdicciones estatales para solicitar medidas provisionales o cautelares, sea antes o después de la constitución del tribunal arbitral.

El artículo 39 (6) del Reglamento de Arbitraje CIADI, tal como quedó reformado luego del 26 de septiembre de 1984, dispone en efecto que, salvo acuerdo en contrario, las partes no pueden solicitar a ninguna autoridad judicial que ordene medidas provisionales $y / 0$ cautelares, antes o después del comienzo del arbitraje. Al contrario, antes de 1984, el sometimiento de una demanda de arbitraje al CIADI no impedía recurrir a las jurisdicciones estatales para demandar medidas provisionales. Observaremos que la exclusión de la competencia judicial no se encuentra en el Reglamento de Arbitraje del Mecanismo Complementario.

Toda solicitud de medidas provisionales ante el juez estatal se encuentra por tanto condicionada al acuerdo de las dos partes. Además, este acuerdo debe incluirse en la convención de arbitraje, lo que parece excluir que pueda ser adoptado en curso de instancia, pero no vemos muy bien qué podría impedir a las dos partes, aceptar voluntariamente la competencia del juez de las medidas provisionales y cautelares.

La prohibición contenida en el artículo 39 (6) del Reglamento de Arbitraje CIADI tiene la vocación de confortar el carácter autónomo de este tipo de arbitraje, siendo el consentimiento a la Convención de Washington excluyente de cualquier otra competencia, $y$ en particular de toda competencia de juris- 
dicciones estatales. Mientras que es un principio del arbitraje comercial que la existencia de un convenio arbitral no impide, en tanto que el tribunal arbitral no se ha constituido, que una parte recurra a una jurisdicción estatal para obtener una medida de instrucción o una medida provisional o conservatoria ${ }^{39}$, las partes en el arbitraje CIADI se encuentran impedidas de recurrir al juez, incluso en caso de urgencia, antes o después de iniciarse el arbitraje.

Esta solución ha venido a poner término a un debate doctrinal sobre el alcance del consentimiento al arbitraje CIADI en relación a las medidas provisionales y cautelares ${ }^{40}$, en la que una parte de la doctrina consideraba que el artículo 26 del Convenio de Washington debía ser interpretado como una renuncia a todo recurso a las jurisdicciones estatales en materia provisional y conservatoria, mientras que la otra se oponía a esta solución por razones prácticas ${ }^{41}$.

Este debate doctrinal encontró eco en el caso Atlantic Triton, en el cual se discutió la competencia de los tribunales franceses para ordenar el embargo de una embarcación respecto de partes que habían celebrado un contrato conteniendo una cláusula compromisoria que hacía referencia al arbitraje CIADI.

En este caso, una sociedad noruega llamada Atlantic Triton había firmado un acuerdo de gestión con la República de Guinea, sobre el equipamiento y la gestión de tres barcos de pesca noruegos que habían sido comprados por Guinea. Atlantic Triton había rescindido dicho contrato alegando la inejecución por parte de Guinea de sus obligaciones financieras, y obtuvo medidas de embargo sobre los barcos, del juez francés. El Estado

39. En este sentido, ver por ejempilo el articulo 1.468 del CPC francés tal como fue reformado por el Decreto del 13 de encro de 2011.

40. E. Gaillard, sobre la decisión de la Cour de Cassation $1^{\circ}$ civ., 18 de noviembre de 1986, JDI 1987 , p. 125; A. Parra, "Pratique et cxpérience du CIRDI n, en Mesures Provisoires et Conservatoires en maricre d'arbitroge intemational, op. cit.; Ch. Brower y R. Goodman, op. cit.; Ch. Schreuer y otros, op. cit., art.26, \$162.

41. G. R. DeLAUse, "ICSID and the Transnational Financial Community", ICSID Revicw, 1986, pp. 239 248; Cl. Schirlutir y otros, op, cit, art. $26, \$ 174$, y las referencias. 


\section{Las medidas provisionales y coutclares: \\ A propósito de cierlos aspeclos recurrentes elt el arbitraje de inversiones}

de Guinea solicitó entonces al juez francés el levantamiento de dichos embargos.

La Courd'appel de Rennes, en una decisión del 26 de octubre de 1984, decidió que el espíritu del Convenio de Washington implicaba una competencia exclusiva de los árbitros del CIADI para conocer sobre toda solicitud de medidas cautelares interpuesta por una de las partes, incluso antes del compromiso de arbitraje.

El tribunal del CIADI, al cual acudió el Estado para reclamar una demanda de daños e intereses contra el inversionista, expresó por su parte una opinión diferente. El tribunal arbitral, en efecto juzgó que,

"si bien, de la Convención de Washington y del reglamento de arbitraje CIADI, efectivamente se desprende que el Tribunal Arbitral tiene competencia para recomendar medidas cautelares, no resulta sin embargo evidente que tal competencia sea exclusiva y prohíba cualquier recurso ante las jurisdicciones estatales, tradicionalmente y casi universalmente reconocidas como siendo las únicas con competencia para ordenar tales medidas" 42 .

La Cour de cassation restableció la armonía al casar la decisión de la Courd'appel de Rennes el 18 de noviembre de 1986. La Cour de cassation en efecto consideró que el artículo 26 -en su redacción anterior a la reforma de 1984- "no pretendín prohibir que las partes se dirijan al juez estatal para demandar medidas cautelares destinadas a garantizar la ejecución del laudo por dictarse"43.

Si la solución adoptada por el artículo 39 (6) presenta la ventaja de preservar la exclusividad del CIADI, ella presenta también el inconveniente mayor de impedir todo recurso a un juez

42. E. Gall.tard, "La jurispradence du CIADI", Ed. Pédone, Paris, Laudo $\$ \S 222-223$ (traducción libre).

43. Cour de Cass. civ. $1^{\circ}, 18$ de noviembre de 1986, JDI 1987.125, nota E. Gaillard, Rev. arb. 1987 p. $3 ! 5$, nota Flécheux.

282 Revista Ecuatoriana de Arbitraje 
para obtener medidas provisionales o cautelares. En la práctica, todo recurso al juez correría de cualquier manera el riesgo de chocar contra la inmunidad de jurisdicción de la que goza el Estado demandado, pero existen situaciones, en particular cuando el Estado es parte en un contrato comercial, en donde dicha inmunidad es susceptible de no ser aplicable. El inconveniente que representa la prohibición de medidas provisionales ante el juez existe en particular en la fase anterior a la constitución del tribunal arbitral. En efecto, el proceso de constitución del tribunal puede a veces tomar un tiempo considerable, y la imposibilidad de obtener medidas urgentes durante este período es susceptible de desviar a las partes del arbitraje CIADI.

El CIADI ha intentado responder a las críticas suscitadas por la prohibición de medidas provisionales antes de la constitución del tribunal arbitral al incluir, en el artículo 39 (5) del Reglamento, una disposición según la cual: "Nada en esta Regla impedirá que las partes, siempre que lo hayan estipulado en el convenio que registre su consentimiento, soliciten a cualquier autoridad judicial o de otra naturaleza que dicte medidas provisionales, antes de la iniciación del procedimiento, o durante la sustanciación del procedimiento, para la preservación de sus respectivos derechos e intereses". Se trata aquí, sin embargo, de un cautère sur une jambe de bois ${ }^{44}$, pues la urgencia con la que las medidas provisionales deben obtenerse es, la mayor parte de las veces incompatible con los plazos de constitución del tribunal arbitral.

En realidad, la única manera de obviar eficazmente la prohibición del artículo 39 es previendo una cláusula a tal efecto en el acuerdo de arbitraje. El CIADI propone a tal fin, la cláusula modelo siguiente:

"Sin perjuicio de la facultad del Tribunal de Arbitraje de recomendar medidas provisionales, cualquiera de las partes de este instrumento podrá solicitar a un tribunal judicial u 44. "cauterizar una piema de madera", hacer algo inúitl (traducción libre). 
otra autoridad que dicte medidas provisionales o precautorias, incluidos embargos, antes de la iniciación del procedimiento de arbitraje o durante el mismo, para salvaguardar sus derechos e intereses" 45 .

Tal cláusula sin embargo no aporta la solución en la hipótesis de los arbitrajes basados en un TBI. Algunos tratados contienen, efectivamente, disposiciones particulares en este sentido ${ }^{46}$, pero la mayoría de ellos son silenciosos respecto a este punto.

Añadiremos que, en la hipótesis de un litigio que surja con ocasión de un contrato de inversiones, el exclusivismo del artículo 39 no puede ser sino imperfecto. En efecto, si la inversión es objeto de un contrato que prevé una cláusula de arbitraje ad hoc o que haga referencia a un reglamento distinto de aquél del CIADI, la parte que desea obtener medidas urgentes podrá actuar a la vez en base al contrato y al tratado.

Un buen ejemplo de este tipo de situaciones viene dado por el contencioso que opuso al grupo Exxon de Venezuela y a la compañía petrolera estatal (PDVSA). Exxon y PDVSA habían firmado un contrato que contenía una cláusula de arbitraje CCI, la cual contenía una cláusula que garantizaba al inversionista contra toda medida adoptada por el Estado que tuviera un efecto expropiatorio. El inversionista, sosteniendo que tales medidas habian sido tomadas en el marco de la nacionalización de las actividades de prospección petrolera en la zona del Orinoco, comienza un procedimiento de arbitraje en el CIADI bajo el fundamento de un tratado bilateral de protección de inversiones ${ }^{47}$, y seguidamente un procedimiento CCI sobre el fundamento de la cláusula contenida en el contrato. Apoyándose en el reglamento de arbitraje de la $\mathrm{CCI}$, que permite a las partes dirigirse al juez estatal para solicitarle medidas provisionales o cautelares ${ }^{48}$, Exxon recurre a las juris-

45. Ver en el sitio Internet del CIADI: hup://icsid.worldbank.org/ICSID/StaticFiles/model-clauses-spa/main-sp̣a.htm

46. Ver sobre esic aspecto, R. ZıADt, op. cit., p. 196, nota 23, citando el ejemplo del TBI Suiza - Kuwait.

47. Mobil Corporation et al c. Venczucla, Caso ARB/07/27, decisiỏn sobre competencia, 10 de junio de 2010.

48. Articulo 23 del reglamento $\mathrm{CCl}$. 
dicciones estatales de Estados Unidos e Inglaterra a fin de obtener ex parte el embargo de ciertos activos de PDVSA ${ }^{49}$.

Sin embargo, los hechos en los que se basa la demanda del arbitraje CCI (iniciado en base a la cláusula del contrato de inversión que garantiza al inversionista contra toda expropiación) eran los mismos que aquellos que fueron invocados ante el CIADI. Siendo las partes diferentes (de un lado, el Estado, del otro, la compañia estatal), el inversionista pudo de esta manera solicitar ante las jurisdicciones estatales las medidas provisionales y cautelares a las cuales el Reglamento del CIADI les hubiera impedido el acceso.

Es la distinción-aquí aparentemente bastante artificial entre reclamaciones en base a tratados y reclamaciones contractualesla que permite al inversionista justificar el recurso a dos tribunales arbitrales mediante demandas probablemente idénticas y basadas sobre los mismos hechos, y de evitar así el artículo 39 del Reglamento CIADI. Será necesario, para asegurar la eficacia del artículo 39, cuando las dos demandas son idénticas y tienen el mismo fundamento jurídico, considerar que la introducción de una demanda ante el CIADI sea tratada como una renuncia a recurrir al juez de medidas provisionales en el marco de un procedimiento paralelo que se base en el mismo fundamento. Tal regla, sin embargo, únicamente aportará la solución al problema entre las mismas partes.

En realidad la regla del artículo 39 es una mala respuesta a una buena pregunta. Si es justificado querer asegurar la exclusividad del arbitraje del CIADI, prohibir toda demanda de medidas provisionales o cautelares es a la vez ineficaz y dañino para la eficacia del sistema. Habría que reflexionar más bien sobre la creación dentro del sistema del CIADI, de un mecanismo de medidas urgentes arbitrales semejante al que prevén los reglamentos de arbitraje de la Cámara de Comercio de Estocolmo y del ICDR, y que la CCI prevé introducir en su nuevo reglamen49. Ver para un resumen del caso: Istip:/venczuclanalysis.com/news/5426. 
to. Semejante sistema permitiría al Centro, en caso de demanda urgente y antes de la constitución del tribunal arbitral, nombrar a un árbitro de emergencia, el cual estaría encargado de dictar en plazos muy breves una orden, la cual podrá a su vez ser confirmada o revocada por el tribunal arbitral, una vez que éste último se haya constituido.

\section{LA CUESTIÓN DE LAS MEDIDAS EX PARTE}

La posibilidad para los árbitros de ordenar medidas provisionales ex parte, es decir, sin debate contradictorio, ha suscitado, como sabemos, un intenso debate en el cual no entraremos en detalle en el marco del presente trabajo ${ }^{50}$. Esta cuestión ha ocupado una parte considerable del tiempo consagrado por el grupo de trabajo sobre arbitraje de la CNUDMI durante la revisión del artículo 17 de la ley tipo CNUDMI51, que ahora prevé la posibilidad de obtener medidas provisionales $e x$ parte ${ }^{52}$. Esta innovación no parece sin embargo haber suscitado un enorme entusiasmo. Actualmente, entre los países que han adoptado el modelo de 200653, sólo Ruanda ha incorporado las nuevas disposiciones sobre medidas $e x$ parte ${ }^{54}$, mientras que Australia excluyó expresamente su aplicación ${ }^{55}$. Añadiremos, como un signo de

50. A favor: G. KAUFMAN-KoILEK " Mesures ex parte et injonctions préliminaire " en Les mesures provisoires dans l'arbitrage commercial intemational. J-M Jacquet et E. Jolivet (Eds), Litec, Paris 2007 p. 92: contra: Y. DeRnins, " L'arbitre et l'octroi de mesures provisoires ex parte ", Cahiers de l'arbitragc, Recucil Vol. II, p. 74, adde del mismo autor " The vicw against a proposal for ex parte interim arbitral relicf n, Disputc Resolution Joumal, agosto-octubre 2003. pp. 61 y ss.; H. VAN HOUTT: “ Ten reasons against a proposal for ex parte interim measures of protection in arbitration $n$. Arbitration International. 2004 vol. 20 , p.. 85-95.

51. Ver en particular: A/CN.9/487; A/CN9.545; A/CN.9/569; A/CN.9/573; A/CN.9.589; A/CN.9/592; A/CN.9/WG.I1/WG.119; A/CN.9/WG.II/WG.121; A/CN.9/WG.11/WG.127; A/CN.9/WG.J1/WG.134; A/CN.9/WG.11/WG.138: A/CN.9/WG.II/WG.141.

52. Articulos 17 B y $17 \mathrm{C}$, y tratandose de las condiciones para acordar órdenes preliminares, ver articulos 17 D y $17 \mathrm{E}$, igualmente aplicables a las medidas provisionsles tomadas contradictoriamente.

53. Es decir, Australia, Georgia, el Estado de Florida, Iflanda, Nucva Zelanda, Ruandia, Esloveria y el Perú (hitp://www. uncitral.org/uncitral/fr/uncitral_texts/arbitration/1985Model_arbitration_status.huml).

54. V. I'Articulo 24 Loi rwandaise relative à l'arbitrage de 2008, qui dispose que " le collège arbitral peut prononcer une injonction préliminaire lorsqu' il considère que la communication préalable de la demande de mesure provisoire à la partie contre faquelle elle est dirigée risque de compromettre l'objectif visć cette mesure $n$

55. V. I'Articulo I8B Intemational Arbitration Act australien de 1974, qui proinibe une telle possibilité « malgré I'Articulo 17B de la Loi-Type n. 
que el escepticismo finalmente predomina al respecto, que la posibilidad de ordenar medidas ex parte no fue retomada en la versión 2010 del Reglamento de Arbitraje CNUDMI.

Los argumentos invocados a favor y en contra de la admisión de medidas $e x$ parte arbitrales son hoy en día conocidos, así que únicamente los recordaremos por memoria.

En primer lugar, para sus detractores tales medidas serían incompatibles con la naturaleza consensual del arbitraje, mientras que sus promotores insisten por el contrario, sobre la naturaleza jurisdiccional del arbitraje y la ausencia de justificación a una restricción de los poderes del árbitro respecto de los poderes del juez ${ }^{56}$.

En segundo lugar, estas medidas corren el riesgo de afectar la imparcialidad de los árbitros a los ojos de la parte destinataria de una medida sobre la cual no ha tenido la oportunidad de expresarse. Pero no podemos pensar que, en las condiciones de extrema urgencia en las que estas medidas son tomadas y tomando en cuenta la instauración inmediata de un debate contradictorio, este argumento sea dirimente. También se ha argumentado que el árbitro, habiéndose pronunciado ex parte, podría seguidamente estar influenciado por su decisión al momento de apreciar el fondo del litigio ${ }^{57}$. Este último argumento reenvía a la cuestión más general de la imparcialidad del juez de las medidas cautelares, llamado seguidamente a conocer sobre el fondo, y debe admitirse pensar que la misma no presenta especificidad particular por lo que se refiere a las medidas ex parte.

Consideramos que el argumento decisivo sin embargo es el de la completa inutilidad de semejantes medidas. El artículo 17 C (5) de la Ley Modelo luego de la revisión de 2006 prevé expre-

56. G. KAUfaAan-KoHter, " Mesures ex parte et injonctions préliminaire " in Les mesures provisoires dans l'arbitrage commercial intemational, prec. p. 92.

57. II. VAN HouTtE, "Ten reasons against a proposal for ex parte interim measures of protection in arbitration " prec. p. 87; Derains, " L'arbitre et l'octroi de mesures provisoires ex parte n, op. cit.p. 15 , A/CN9.523; A/CN.9/WG.II/WG.129. 
samente que las medidas unilaterales no son susceptibles de ejecución inmediata. YVES DERAINS explicó con perfecta claridad que:

\begin{abstract}
"al estar las decisiones de los árbitros desprovistas de fuerza ejecutoria per se, la intervención del juez resulta indispensable, después de la del árbitro. Pero, si no podemos evitar la intervención del juez, entonces resulta más rápido y eficiente dirigirse directamente a él. Es esto lo que hacen las partes cada vez que les resulta posible. Cuando no es posible, las partes estiman preferible dirigir la solicitud de medidas provisionales al tribunal arbitral enviando una copia a la parte adversa, e invitando a los árbitros a ordenar a éste último no modificar el statu quo antes que el tribunal se haya pronunciado sobre la medida solicitada. El tribunal arbitral podrá entonces ordenar en pocas horas que el statu quo sea congelado y seguidamente, organizar en un plazo breve un procedimiento expedito pero contradictorio, sobre la medida solicitada. La autoridad y el poder de persuasión de los árbitros son generalmente suficientes para permitir el mantenimiento de la situación en su estado, en la espera de la decisión. Si tal no es el caso, el procedimiento ex parte ante el tribunal arbitral no habrá servido de nada, ya que la solicitante de la medida tendrá que dirigirse a continuación, al juez del exequátur, al cual hubiera sido más simple dirigirse desde el primer momento." 58
\end{abstract}

Como señaló Yves DeraINS, en la práctica, cuando existe una urgencia extrema, el tribunal arbitral reaccionará inmediatamente a una solicitud de medidas cautelares, acordando a la otra parte un plazo para poder responder y ordenándole al mismo tiempo no modificar el statu quo hasta la decisión del tribunal. Obtenemos así el mismo resultado, sin los inconvenientes inherentes a cualquier distorsión del principio del contradictorio.

Este debate, en cualquier caso, no tiene razón de ser en el arbitraje CIADI. El artículo 39 (4) del Reglamento de Arbitraje

Drrains, " L'arbitre et l'octroi de mesures provisoires ex parte ", op. cil., pp. $7+75, \S 4$. 
del CIADI impone, en efecto, a los árbitros no conceder medidas provisionales sino "después de dar a cada parte una oportunidad para que haga presente sus observaciones". Cuando el arbitraje está sometido al Reglamento de la CNUDMI o de otra institución arbitral distinta del CIADI, la cuestión sin embargo podría plantearse. Nos parece que las consideraciones que fueron recordadas más arriba, que conducen a alimentar serias dudas sobre la legitimidad de las medidas ex parte en el arbitraje comercial, son entonces más convincentes todavía frente a un Estado soberano, en el marco de un arbitraje basado en un tratado.

\section{EL PODER DE LOS ÁRBITROS PARA DICTAR ÓRDENES $Y$ PENAS COERCITIVAS}

Es generalmente admitido que los árbitros disponen del poder de dictar a las partes órdenes de hacer o no hacer ${ }^{59}$. Estas órdenes pueden ser relativas al comportamiento procesal de las partes o a la ejecución de sus obligaciones sustanciales; nosotros analizaremos aquí en primer lugar, la cuestión más particular de las órdenes de no proceder (anti-suit injunctions) dictadas por los árbitros en arbitrajes de inversiones, en particular, en presencia de procedimientos paralelos (5.1). A continuación, abordaremos el aspecto relativo al poder de los árbitros de ordenar penas coercitivas para asegurar la eficacia de sus decisiones (5.2).

\subsection{Anti-suit injunctions y procedimientos paralelos}

La multiplicación de los procedimientos paralelos ha hecho frecuentes las solicitudes de órdenes dirigidas a preservar la competencia del CIADI. Es posible que el tratado sobre el cual se

59. En Francia, ver Cass. Civ. 25 de julio de 1.882, DP 1883, 243; Rennes, 26 de scptiembre de 1984, Rev. Arb. 1986, 441, nota J. - P. ANCrL; Paris, 24 de mayo de 1991, Rev. Arb. 1992, 638, nota J. PELLeRIN; Paris, 7 de octubre de 2004, JDI 2005, 341, nota de A. MOURRE y P. PLDONE. En derechocomparado ver A. MoURre "Judicial penalties and specific performance in international arbitration". en Interests,Auxiliany and Aliematives remedies in International Arbitration. Dossiers V, ICC Publication, 2008, Paris, pp. 53-79. 
haya formado el arbitraje CIADI incluya una cláusula fork in theroad o una cláusula paraguas, y que sin embargo se haya iniciado un procedimiento paralelo.

La jurisprudencia, en un primer momento dudó sobre la cuestión del poder de dictar órdenes de los árbitros, en particular, en vista de las incertidumbres sobre la exclusividad de la competencia del Centro60. Los árbitros del CIADI hoy en día admiten sin problema que los procedimientos arbitrales iniciados bajo la tutela del Centro prevalecen sobre los procedimientos locales ${ }^{61}$, y admiten su poder para ordenar a las partes renunciar a procedimientos paralelos. Sin embargo, para ello es necesario que dichos procedimientos paralelos sean de tal naturaleza que puedan causar un daño a la eficacia de la competencia del CIADI; así, toda orden dirigida a suspender un procedimiento paralelo supone una apreciación de la naturaleza de los procedimientos en causa y de su vínculo con el procedimiento arbitral62.

El tribunal del caso Autopistas c. Venezuela claramente afirmó su poder de ordenar a una parte que renunciara a un procedimiento paralelo: "Al acordar someterse exclusivamente a arbitraje, ambas partes aceptaron abstenerse de iniciar procedinientos ante un tribunal distinto de aquel al que en forma conjunta se encomendó la resolución de la controversia." 63

Existen numerosos ejemplos de tales órdenes. En el caso CSOB c. Eslovaquia, el tribunal recomendó a título conservatorio que se suspenda el procedimiento de quiebra en curso ante la justicia eslovaca ${ }^{64}$. En el caso City Oriente, el tribunal ordenó al demandado suspender ciertos procedimientos de cobro inicia-

60. Ver L. MALINTOPPI, "Provisional measures in recent ICSID proccedings; what partics request and what tribunals order", op. cit., p. 166 y las referencias en nota al pie 115.

61. Victor Pey Casado y Fundación Presidente Allende c. República de Chile, Caso CIAD1 ARB/98/2, prec., $\$ 56-60$.

62. Plama Consortium Limited c. Bulgaria, prec., \$ 42; Victor Pcy Casado y Fundaciỏn Presidente Allende c. República de Chile, Caso CIADI ARB/98/2, prec., $\$ 60$.

63. Autopista Concesionada de Venezuela, C.A. c. Venezucla, Casa ClADI ARB/00/5, Laudo del 23 de septiembre de 2003, \$ 205.

64. CSOB c. Eslovaquia, Caso CIAD1 ARB/97/4, orden procesal n ${ }^{\circ} 4$ del 11 de enero de 1999. 
dos en virtud de la misma ley sobre hidrocarburos a la cual se hacía referencia en el arbitraje de inversiones. En este caso, la obligación de entregar una parte de los ingresos excepcionales recibidos por el inversionista al estado se derivaba de la ley, y el Estado sostenía que un tribunal arbitral no tendría el poder necesario para paralizar los efectos de una ley. El tribunal consideró sin embargo que el inversionista tenía derecho a mantener el statu quo hasta que el laudo sobre el fondo fuera dictado. El tribunal estimó entonces que el artículo 46 del Convenio de Washington le otorgaba el poder de ordenar al Estado que suspendiera los procedimientos litigiosos de cobro ${ }^{65}$.

Más recientemente, en el caso Chevron c. República de Ecuador, los árbitros ordenaron a título provisional al Estado que se abstuviera de ejecutar las decisiones dictadas por los tribunales estatales ecuatorianos 66 .

Ciertos tribunales han ido aún más lejos, llegando a prohibir a una parte iniciar procedimientos en el futuro. Así, en el caso MINE c. Guinea, el tribunal arbitral no solamente ordenó a una parte desistir de todo otro procedimiento en curso, sino que también le ordenó no iniciar nuevos procedimientos ${ }^{67}$. Esta tendencia, que puede parecer excesiva, es sin embargo minoritaria. El tribunal del caso SGS c. Pakistán se negó así a ordenar al Estado abstenerse de todo recurso futuro a una jurisdicción nacional ${ }^{68}$. De la misma manera, el tribunal del caso Plama se negó a prohibir a una parte a iniciar futuros procedimientos ${ }^{69}$.

65. City Oriente, Ltd. c. Ecuador, decisión sobre la suspensión de medidas provisionales del l 3 de mayo de 2008, 559.

66. El tribunal ordenó al Estado "tomar todas las medidas a su disposición para suspender o provocar la suspensión de la ejecución o reconocimiento con 0 sin Ecuador, de cualquier decisión contraria al Primer Demandante en el caso Lago Agrio" (traducción libre), Orden de 9 de febrero de 2011. (hitp://italaw.com/documents/ChevronAndTexacoVEcuador_InterimMeasuresOrder.pdf).

67. Maritime International Nominees Establishment c. République de Guinćc, Caso CIADI ARB/84/4 ; Tokyos Tokelès, prec. $\S 3$

68. SGS Sociéci Géneirale de Surveillance S.A. c. República Istaimica de Pakistán, Caso CIADI ARB/01/13, orden de procedimiento $n^{\circ} 2,16$ de octubre de 2002, ICSID Review, 2003, p. 293; en contra ver cl easo Tokyos Tokeles,prec.

69. Plama Consortium Limited c. Bulgaria, prec. $\S 43$. 


\section{Las inedidas provisionales y cautelares: \\ A propósito de cierlos aspectos recurrenies en el arbitraje de inversiones}

Podemos preguntarnos si tales medidas pueden ser dictadas, cuando la competencia del tribunal arbitral ha sido impugnada, sobre la base de una verificación prima facie de la competencia de los árbitros. Esta cuestión fue analizada más arriba, pero podemos interrogarnos si, en vista de que ella tocaría al derecho de actuar en justicia de una de las partes, una 'orden de no proceder' no merecería una verificación más profunda de la competencia del tribunal arbitral. Esto es lo que parece haber pensado el tribunal arbitral del caso Autopistas, el cual, sin embargo, había recibido la solicitud cuando ya había establecido su competencia respecto del fondo:

"En tanto se interpongan objeciones a la jurisdicción y no se resuelva al respecto, podria argumentarse que la Parte tiene derecho a recurrir a otras instancias. Sin embargo, dicho argumento pierde toda vigencia una vez emitida la decisión que establece que el Tribunal tiene competencia. En el presente caso, se inició el procedimiento ante la Corte Suprema con posterioridad a la emisión de la Decisión sobre competencia." 70

Sin embargo no parece seguro que semejante restricción estuviese justificada. Al igual que para cualquier otra medida conservatoria, la anti suit injunction debe poder ser dictada, en caso de ser necesario, tan rápidamente como sea posible, en base a una verificación sumaria de la competencia del tribunal.

La cuestión del poder de dictar órdenes de los árbitros en presencia de procedimientos paralelos se presentó respecto de demandas múltiples fundadas sobre un contrato y un tratado. En el caso SGS v. Pakistán, el tribunal ordenó a Pakistán suspender el procedimiento arbitral CCI que se desarrollaba en su territorio, según el motivo que las demandas presentadas ante el tribunal CCI eran susceptibles de tener una repercusión sobre aquellas sometidas al CIADI71.

70. Autopista Concesionada de Venezuela, C. A. c. Venezucla, prec., Laudo de 23 de septiembre de 2003. $\$ 205$.

71. SGS Sociétí Gínírale de Surveillance S.A. c. República Islámica de Pakistán, orden de procedimiento $\mathrm{n}^{\circ} 2,16$ de octubre de 2002. ICSID Report p. 388. 
Ciertas demandas sin embargo son más problemáticas. En el caso Plamn, se había solicitado al tribunal arbitral ordenar al Estado que hiciera lo necesario para que sus tribunales estatales pusieran fin a los procedimientos en curso que implicaran a terceros. El tribunal rechazó la demanda, indicando que era "reticente a la idea de recomendar a un Estado que ordenase a sus Tribunales denegar el derecho a terceras partes para interponer demandas para poder acceder a sus recursos judiciales. "72

\subsection{Poder de los árbitros para dictar órdenes, multas coerci- tivas y ejecución específica}

Es generalmente admitido que los árbitros disponen del poder de imponer multas coercitivas para asegurar la eficacia de sus decisiones ${ }^{73}$. Las multas coercitivas plantean sin embargo problemas diferentes según que su objeto sea procesal o que ellas se refieran a una orden relativa a la ejecución de obligaciones sustanciales de las partes.

Tratándose de órdenes de naturaleza procesal, es poco habitual que las mismas vengan acompañadas de multas coercitivas. Es posible imaginar, sin embargo, que sean dictadas multas coercitivas en materia procesal, por ejemplo en materia probatoria, cuando se trata de obtener la producción de un documento cuya existencia ha sido establecida con certeza. Respecto de dichas medidas, no existe ninguna razón para hacer una distinción entre arbitraje comercial y arbitraje de inversiones.

Dicho lo anterior, sin embargo, es cierto que en el arbitraje CIADI, la imposición de multas coercitivas puede parecer difícilmente compatible con la caracterización de la decisión de los

72. Plama Consortium Limitcd c. Bulgaria, prec. $\$ 46$.

73. Sobre el conjunto de este tema, ver A. Mourre "Judicial penalties and specifie performance in international arbitration", en Interests, Auxiliary and Alternatives remedies in International Arbitration, Dossiers ICC vol. V, ICC Publication, 2008, Paris, pp. 53-79; y el mismo artículo actualizado en español "Multas coercitivas y ejecución en especic en arbitraje internacional" en Spain arbitration Review, Madrid, Wolter Kluwers, $N^{\circ} 10 / 2011$. 
árbitros como una "recomendación", según resulta del artículo 47 del Convenio de Washington y del artículo 39 del Reglamento de Arbitraje CIADI. Sin embargo, en materia de procedimiento, las decisiones del tribunal están sometidas al artículo 19 en vez de al artículo 39 del Reglamento ${ }^{74}$. Y el artículo 19 permite al tribunal dictar las órdenes necesarias para conducir el procedimiento. Tales órdenes deberían, por tanto, poder venir acompañadas de multas coercitivas.

La situación es diferente respecto de las multas coercitivas asociadas a las obligaciones sustanciales de las partes. En efecto, la orden de hacer o de no hacer, en tales casos es dictada en base al artículo 47 del Convenio de Washington y del artículo 39 del Reglamento, y por lo tanto constituye una "recomendación".

Aunque los tribunales arbitrales han despojado en gran medida de contenido la distinción entre orden y recomendación, en el sentido de que esta última es obligatoria para las partes al mismo nivel que una orden, nos cuesta imaginar que una recomendación pueda venir acompañada de una multa coercitiva.

A esto se añaden las dificultades inherentes a la ejecución en especie de las obligaciones por una parte. En efecto, cuando ella se dirige a asegurar la ejecución por una de las partes de sus obligaciones substanciales, la multa coercitiva está íntimamente ligada a la posibilidad de ordenar la ejecución en especie de las obligaciones litigiosas. Sin embargo, estas no siempre son permitidas por la ley que regula dichas obligaciones, en particular, cuando tales obligaciones tienen un fuerte carácter intuitu perso$n a e^{75}$.

74. Las decisiones adoptadas por el tribunal arbitral en aplicación del articulo 43 del Convenio caen bajo la esfera del articulo $19 \mathrm{del}$ Reglamento y no del artículo 39. Ver sin embargo,Biwater Gaufr (Tanzanic) Limited c. Tanzania, prec, nota 5, addc. Ch. SCIIRfuer y otros, The ICSID Convention : A commentary on the Convention onthe Settlement of Investment Disputes befween States and Nationals of Other States, prec. nota $5, \S 80$, p. 780.

75. A. MOURRE, "Judicial penalties and specific performance in international arbitration" op, cit., pp. 65-70. 
En lo que se refiere más particularmente al arbitraje en materia de inversiones, la ejecución específica de las obligaciones de los Estados ha planteado dificultades particulares, especialmente en los casos de expropiación, en cuanto a la compatibilidad de las medidas de restitución con la soberanía de los Estados.

Esta cuestión fue abordada en el caso BP c. Libia, el tribunal arbitral decidió que:

"Una regla de razón por tanto, dicta una solución que es conforme tanto con el derecho Internacional, tal como lo evidencia la práctica de los Estados, como con el Derecho de los Tratados y con los principios que rigen los Derechos de Contratos, Inglés y Estadounidense. Tal es el caso, cuando al ejercer un poder soberano, el Estado ocasiona una violación fundamental de un acuerdo de concesión al no reconocerlo a través de una nacionalización de la empresa y sus activos de manera permanente. El concesionario no podrá reclamar la ejecución específica del acuerdo y la reposición de sus derechos contractuales por parte del Gobierno, sino que su única opción será reclamar una indemnización por daños."76

El tribunal del caso Occidental Petroleum c. República de Ecuador 77 igualmente se negó a ordenar las medidas de ejecución específica que le fueron solicitadas. Refiriéndose al laudo $B P C$. Libia precitado, el mismo rechazó la demanda según el siguiente motivo: "la ejecución específica será $[. .$. J rechazada si ella implica una carga excesiva para la parte a la que se le dirige" $78, \mathrm{y}$

"imponer a un Estado soberano la reposición de un inversionista extranjero en su concesión, después de una nacionalización o de la rescisión de la licencia de concesión o de su

76. BP Exploration Company (Lybia) Limited v Libyan Arab Republic, 52 ILR 297 (1974) p. 354 (traducción libre).

77. Occidental Petroleum Corporation et Occidental Exploration and Production Company c. República de Ecuador, Caso CIADI ARB/06/11, decisión sobre medidas provisionales, 17 de agosto de 2007, \$ 84.

78. Occidental PetrolcumCorporation y Occidental Exploration and Production Company c. República de Ecuador, prec. $\$ 82$, (traducción libre). 
contrato por parte del Estado, constituye una reparación desproporcionada a la interferencia con la soberanía del Estado comparada con la indemnización pecuniaria."79

No podemos excluir, sin embargo, que la jurisprudencia evolucione. Observaremos al respecto que el tribunal del caso City Oriente c. República de Ecuador recientemente ordenó una medida provisional cuyo fin consistía precisamente en preservar el derecho del demandante a una futura decisión de ejecución específica ${ }^{80}$. Ciertamente, la Convención de Washington parece prever únicamente la ejecución de laudos de condenas pecuniarias $^{81}$, pero un laudo de ejecución específica acompañado de una multa coercitiva pudiera perfectamente ser calificado como tal.

\section{LA CONSTITUCIÓN DE GARANTÍAS}

En su origen, la cautio judicatum solvi era una garantía financiera exigida a los extranjeros que deseaban recurrir a una jurisdicción francesa contra una persona francesa, a fin de garantizar el pago de los gastos que pudiera causar el proceso y a los daños e intereses a los que pudiera condenarse al demandante en caso de que no prosperara su acción ${ }^{82}$. Esta exigencia, conocida en los países anglosajones bajo el nombre de security for costs, ha sido

79. Occidental Petrolcum Corporation y Occidental Explorstion and Production Company c. Repúblical de Ecuador, $§ 84$, (traducción libre).

80. City Oriente L.td. c. Petroccuador y la República de Ecuador, Caso CIADI No ARB/06/21. Decisión sobre las medidas provisionales, el tribunal recomendỏ asi que: "La República de Ecuador y la Empresa Estatal Petrúleos del Ecuador (Petroecuador) deberín abstenerse de [...] Involucrarse, iniciar o continuar en cualquier otra conducta que pueda directa, o indirectamente afectar a alierar ba situación legal acordada según cl Contrato de 29 de marzo de 1995, scgún lo acordaron y firmaron las partes."

81. El articulo 54 (1) del Convenio de Washington dispone asi que: "Todo Estado Contratante reconocerá al laudo dietado conforme a este Convenio caricter obligatorio y hará ejecutar dentro de sus territorios las obligaciones pecuniarias impuestas por el laudo como si se tratare de una sentencia firme dictada por un tribunal existente en dicho Estado."

82. Recordaremos que la cautio judicatum solvi ha desaparecido de manera general en Derecho francés desde el Decreto n 72-684 de 20 de julio de 1972: Ver G.Droz., "La sentinelle perduc ou la disparition subreptice de la cautio judicatum solvi”: Rép. Commaille 1973, p. 281 s.; Desaparición confirmada por la Ley $\pi^{\circ} 75-596$ de 9 de julio de 1975 (Journal Officicl 10 de julio de 1975; Rev. crit. DIP 1975, p. 808) que abrogó el Articulo 16 del Código Civil; sobre la condena de la cautio judicatum solvi por el ordenamiento juridico comunitario, ver CICE, I de julio de 1993: Rev. crit. DIP 1994, p. 633, nota G. Dkoz. 
considerada incompatible por la cour de cassation francesa, con el principio de derecho de acceso a la justicia, protegido por la Convención Europea de Derechos Humanos ${ }^{83}$.

En el arbitraje, la institución ha sido generalmente admitida en los países de tradición anglosajona ${ }^{84}$, aun cuando ciertos de entre ellos la hayan descartado ${ }^{85}$. La jurisprudencia, por su parte, está dividida, ciertos tribunales admiten las demandas de security for costs ${ }^{86}$ y otros las niegan, en ausencia de acuerdo de las partes al respecto ${ }^{87}$.

En materia de inversiones, generalmente es el Estado demandado el que solicitará tal medida. El tribunal arbitral del caso Atlantic Triton c. Guinea ya había rechazado una solicitud en este sentido ${ }^{88}$. El tribunal del caso Libananco c. Turquía también rechazó una demanda del Estado dirigida a que se ordenase al demandante constituir una garantía bancaria por un monto de 5 millones de dólares para protegerse contra el riesgo de que el inversionista - que según el Estado no era sino un simple caparazón vacío- no pudiera contribuir con los gastos del arbitraje ${ }^{89}$. En el caso Maffezini, España también formuló, sin éxito, una solicitud de que se constituyera una garantía bancaria para asegurar la participación del demandante en los gastos del procedimiento 90 .

83. Ver Cour de Cassation $I^{\circ}$ civ. 16 de marzo de 1999, Pordéa, Rev. Crit. DIP2000, p. 224 y crónica de G. Droz, "Variations Pondía (à propos de l'arrêt de la Cour de Cassation, Ire chambre civile, du I6 mars 1999 ", pp. 181 y ss. JDI 1999, p. 774, obs. A. Huct.

84. Ver el articulo $38.3 \mathrm{del}$ Arbitration Act de 1996; el Articulo $12.1 \mathrm{de} \mathrm{la} \mathrm{International} \mathrm{Arbitration} \mathrm{Act}$ de Singapur.

85. Ver Lindow c. McGill Barton Marine Lid, CPI3-SD/02, Auckland High Court, Nueva Zelanda, I de noviembre de 2002, "cl Articulo 17 no confiere al árbitro el poder de ordenar [el page] de una caución para gastos de procedimiento"; Yicldworth Eng 'rs c. Amhold \& Co. Lid., 1992, HKLR 34, H.K. High Court, S, Ct, 1991, "el tribunal arbitral no ticne el poder de ordenar [el pago] de una caución para los gastos del procedimiento cn virtud de la Ley-tipo, salvo autorización expresa de las partes",

86. Ver Caso $\mathrm{CCl} \mathrm{n}^{\circ}$ 8223, laudo parcial, ICC Bulletin Vol. II n० 1, 2000, p. 77; Caso Cámara de Comercio de Zurich n ${ }^{\circ} 415$, orden, 20 de noviembre de 2001, en 20 ASA Bull, 467.2002.

87. Orden No. 6 en Caso Cámara de Comercio de Zurich de 12 de noviembre de 1991, 13 ASA Bull. 84 . 90, 1995.

88. V. P.D. Friedland, "Provisional Measures in ICSID Arbitration", Arbitration International, vol. 2, $\mathrm{n}$ " 4, 1986 y las ref. pp. 342-345.

89. Libananco Holdings Co. Limited $\mathrm{c}$ Turquia, decisión sobre cuestiones preliminares de 23 de junio de $2008, \$ 31$.

90. Emilio Agustin Maffezini c. el Reino de España, prec., Resoluciön procesal n² 2 \$§; 15-16. 


\section{Las medidas provisionales y cautclares: \\ A propósito de ciertos aspectos recurrentes en el arbitraje de imoersiones}

Los árbitros parecen entonces haber rechazado sistemáticamente este tipo de demandas, aún si el tribunal del caso Libananco parecía no querer excluirlas en su principio, al indicar que la misma no podría admitirse sino en situaciones extremas en las que alguna de las partes corriera el riesgo de sufrir daños irreparables ${ }^{91}$.

En realidad resulta bastante difícil para un tribunal arbitral, al comienzo del procedimiento, admitir tales solicitudes de security for costs. Si bien es cierto que podría admitirse tal solicitud únicamente sobre el fundamento de un análisis de los recursos del demandante, los árbitros generalmente temerán que las mismas sean interpretadas como un signo de desconfianza respecto del demandante, el cual será susceptible de degradar considerablemente el clima de buena cooperación entre las partes en el arbitraje.

No obstante, tomando en cuenta los costos, a veces muy importantes, que puede generar un arbitraje CIADI, es cierto que determinados demandantes personas físicas, o ciertos vehículos corporativos a través de los cuales los inversionistas deciden estructurar su demanda, no disponen de la capacidad financiera necesaria para asegurar el reembolso de tales costos en caso de que la acción sea rechazada y que el tribunal estimase que el Estado tiene derecho a ser indemnizado.

Por otra parte, no existen razones para pensar que las medidas de security for costs deberían ser excluidas como cuestión de principio en materia de protección de inversiones. Cuando el inversionista y el Estado están vinculados por un contrato de inversión, ciertamente podemos considerar que dicho Estado ha aceptado contratar con este último, con todos los riesgos que ello implique, y no será entonces sino en caso de una degradación notoria de la situación de su contratante, que una medida de security for costs pudiera ser contemplada. Pero cuando se trata

91. Libananco Holdings Co. Limited c/ Turquia, Decisiön sobre cuestiones preliminares de 23 de junio de 2008, $§ 57$ 
de un arbitraje iniciado en base a un tratado, no hay razones para hacer pesar sobre el Estado un riesgo que él no ha aceptado, más aun considerando que actualmente ciertas demandas de arbitraje son financiadas por terceros cuya identidad no siempre es revelada ${ }^{92}$.

Por tanto, no siempre será ilegítimo, tomando en cuenta ciertas desviaciones del sistema, que los Estados deseen protegerse contra tales riesgos. Más aun, los árbitros serán la mayor parte de las veces reticentes, por las razones analizadas más arriba, a admitir las demandas de security for costs. Ciertamente resultaría chocante, en determinadas situaciones, exigir a la víctima de una expropiación constituir una garantía bancaria, pero hay otros casos en los que tales medidas pudieran justificarse.

Podemos entonces desear que los árbitros se muestren más audaces en este sentido.

92. Ph. PINSOLLE, “ Le financement de l'arbitrage par les tiers ", Rev. arb 2011 n², p. 385. 